\title{
Risk of Squamous Cell Carcinoma of Esophagus and its Relation to Consumption of Antioxidant Vitamins in Kurdistan Province
}

\author{
Seyedeh Sameneh Hassani, ${ }^{1}$ Bahare Hajizadeh, ${ }^{2}$ Majid Hajifaraji, ${ }^{3}$ Anahita Hoshyarrad, ${ }^{2}$ \\ Roya Aghazadeh, ${ }^{1}$ and Bahram Rashidkhani, ${ }^{4,}$ \\ ${ }^{1}$ Departmemt of Nutrition, International Branch, Shahid Beheshti University of Medical Sciences, Tehran, IR Iran \\ ${ }^{2}$ National Nutrition and Food Technology Research Institute, Shahid Beheshti University of Medical Sciences, Tehran, IR Iran \\ ${ }^{3}$ Departmemt of Nutrition, National Nutrition and Food Technology Research Institute, Shahid Beheshti University of Medical Sciences, Tehran, IR Iran \\ ${ }^{4}$ Department of Community Nutrition, Faculty of Nutrition and Food Sciences, Shahid Beheshti University of Medical Sciences, Tehran, IR Iran \\ *Corresponding author: Bahram Rashidkhani, Department of Community Nutrition, Faculty of Nutrition and Food Sciences, Shahid Beheshti University of Medical Sciences, Tehran, \\ IR Iran. E-mail: rashidkhani@yahoo.com
}

Received: July 16, 2012; Accepted: August 16, 2012

Background: Esophageal cancer is the eighth most common cancer and the sixth cause of cancer death worldwide. Among the major risk factors for this disease lack of certain vitamins and minerals including antioxidant vitamins are considered.

Objectives: This study examined the relationship between antioxidant vitamins including vitamins A, E and C and risk of squamous cell carcinoma in Kurdistan.

Patients and Methods: This case-control study was based on dietary patterns of 143 patients including 47 cases and 96 controls. Data were collected by food frequency questionnaire and nutritional value of dietary patterns intake was determined in the two groups by using $\mathrm{N} 4$ (nutritionist IV) software. Statistical data analysis was performed using SPSS-16 and using independent t-test, $\chi^{2}$ and logistic regression.

Results: The result of logistic regression analysis showed an inverse relation between intake of vitamin $\mathrm{E}$ and risk of squamous cell carcinoma $(\mathrm{P}=0.01)$. Also the risk of esophageal cancer in people who received mean of $141 \mathrm{mg} /$ day of vitamin C compared with those with average intake of $125 \mathrm{mg} /$ day had a $98 \%$ decrease $(\mathrm{P}=0.01)$. There was no association between intake of vitamin $\mathrm{A}$, beta carotene and alphatocopherol with risk of squamous cell carcinoma.

Conclusions: Results suggest that antioxidant vitamins can possibly play a protective role in preventing risk of squamous cell carcinoma.

Keywords: Micronutrients; Vitamins; Esophageal cancer; Squamous cell carcinoma

\section{Background}

Cancer is one of the major causes of deaths in developing countries and its prevalence is rising by changing their lifestyle toward the westernized [1]. Esophageal squamous cell carcinoma (ESCC) is the eighth common cancer (among the ten common cancers in the world) and the sixth cause of cancer death in the worldwide. Despite the recent increased detection of disease, the mortality rate is still at a high level. According to statistical data of 2008 , approximately 400,000 people had died due to esophageal cancer all over the world, which $80 \%$ of the mortality happened in developing countries [2]. Iran is one of the high risk areas of esophageal cancer prevalence, so that in some regions such as Golestan province, the incidence of this disease is higher than the global average. Esophageal cancer has estimated the seventh common cancer between men ( 7.4 cases per 100,000 persons) and the forth common cancer between women (6.3 cases per 100,000 persons) in our country.

The major risk factors of ESCC are: age, inheritance, job, smoking and alcohol, obesity, refluxes, achalasia, human papillomavirus (HPV) and helicobacter pylori, hot drinks intake, consumption of foods that consist of nitrosamines and aromatic hydrocarbon, low intake of fruit and fresh vegetables and lack of some vitamins and minerals such as C, A and E vitamins [3]. Although, recently the researchers paid more attention to the role of diet in the appearance of cancer and considered the various aspects of diet in relation to that, but there was a little attention to the role and relationship of micronutrients in the prevalence of different cancers. Also, there have been a very limited number of studies on this field in Iran and only a small number of studies have investigated the relationship between micronutrients intake and esophageal cancer [4-6]. Furthermore, there is no study in this field in Kurdistan province.

\section{Objectives}

The aim of the present case-control study is therefore, to evaluate the relation of antioxidant vitamins intake such as $\mathrm{C}$, A and $\mathrm{E}$ and cancer of ESCC in Kurdistan province.

Copyright (C) 2015, Zahedan University of Medical Sciences. This is an open-access article distributed under the terms of the Creative Commons Attribution-NonCommercial 4.0 International License (http://creativecommons.org/licenses/by-nc/4.0/) which permits copy and redistribute the material just in noncommercial usages, provided the original work is properly cited. 


\section{Patients and Methods}

In this case-control study, the samples were selected among people who referred to the major hospitals of Kurdistan province by systematic sampling method. First of all newly diagnosed patients with ESCC in Kurdistan province were identified during the study and those who had entrance criteria, were enrolled. Controls were frequency-matched with cases according to sex and age (5 year's groups). Cases were patients age 40 - 75 years, who visited major general hospitals and had incident histologically-confirmed ESCC. Cases did not have history of carcinoma of other sites and were interviewed within 6 months after their ESCC was diagnosed. Controls were chosen from individuals admitted to the same hospitals as the cases for neurosurgery, corrective surgery and appendix surgery or orthopedic, ears and throat and nose problems. Controls had no history of each type of cancer and they did not follow a special diet. Generally, 50 patients with ESCC and 100 hospital controls were interviewed face to face by professionally trained interviewers using questionnaires which evaluated socio-demographic characteristics (age, sex, education, and smoking). Additionally, weight and height of the participants were measured. Also, the usual dietary intakes of each person during the last year (for cases, 1 year before diagnosis of the disease and for the controls, 1 year before interview) were collected by a validated semi-quantitive food frequency questionnaire (FFQ) through the interview. Participants were asked to report their consumption frequency on daily, weekly, monthly basis [7]. The FFQ were consisted of 125 Iranian food items. Relative reliability and validity of the questionnaires were evaluated in Tehran province before and the results of previous studies showed a good relative reliability and validity (between $39.6 \%$ and $68.3 \%$ in men and between $39.6 \%$ and $54.1 \%$ in women) for evaluation of food intakes $[8,9]$.

Then by using the collected data through FFQ, the nutritional value of dietary patterns intake was determined in the two groups. In this way, consumption value was calculated for each reported time. Since the consumption value was reported based on serving size or scale of household consumption, first, grams of per serving was determined using the book (scale of household) and then was multiplied in frequency of consumption. In the present study, the consumption frequency on daily basis was considered as the compare unit and the consumption frequency based on week, month and year was converted to day. The consumption gram for each food item was entered into Excel program. N4 (nutritionist IV) software was used to determine the nutritional value of dietary patterns intake. Each food item was coded and entered to $\mathrm{N} 4$. So the nutritional value of dietary patterns intake was calculated for every individual.

The Statistical data analysis was performed using SPSS-16. The mean and standard deviation were used to describe the quantitative variables. Also, Klomogrov-
Smirnov test was used to assess the normalization of the quantitative data and independent t-test was used to consider the relationship between quantitative and qualitative variables. Also $\chi^{2}$ and Fisher tests were used to compare the distribution of qualitative variables between the groups. The logistic regression was used to find the relationship between nutrient intakes and risk of esophageal cancer after controlling disturbing factors of cooking method, reflux signs, family background, eating speed, food preference, job, and BMI. Finally, the odds ratio (OR) and 95\% confidence intervals (CI) for the risk of ESCC were estimated in relation with nutrient intakes. Also residual method was used to consider the effect of energy.

\section{Results}

The distribution of the cases and controls by socio-demographics and selected risk factors are shown in Table 1. By design, age and sex distributions were similar among cases and controls. The mean age was 58 years and the total number of samples was 143 (87 females and 56 males). The male to female ratio was obtained 6/1.

The results showed that, there was a significant relationship between job, reflux, family back ground, cooking method, eating speed, food preference, BMI and pepper consumption variables and risk of ESCC. Also, the controls had a higher BMI and 34\% of cases and 9\% of controls had reflux signs and only $9 \%$ of cases had history of esophageal cancer in their family.

The mean of antioxidant vitamins intake in cases and controls is shown in Table 2. Cases consumed lower level of vitamin A, $\beta$-carotene, vitamin $\mathrm{E}$ (consist of all isomers) and vitamin $C$ compared to the controls. However, the average intake of $\alpha$-tocopherol (the most active isomer of vitamin E), were similar in the two groups.

The regression analysis was done separately between esophageal cancer as a dependent variable and every single nutriment as independent variables and then the nutriments were analyzed simultaneously in a model along with disturbing factors. Table 3 shows the results indicates that, in relation to vitamin A, the risk of ESCC in the third tertile (mean intake of $1.36 \mu \mathrm{gRE}$ ) compared to the first tertile (mean intake of $1.12 \mu \mathrm{gRE}$ ) was significantly reduced in base model $(P=0.02)$, which was not significant in the fully-adjusted model.

There was no relation between $\alpha$-tocopherol and risk of ESCC, but a significant inverse relationship between ESCC risk and higher intakes of vitamin $\mathrm{E}$ observed in both base and fully-adjusted models (base $\mathrm{P}=0.01$ and fully-adjusted $\mathrm{P}=0.005)$. Also being in the highest tertile of $\beta$-carotene $(8.01 \mu \mathrm{gRE})$ reduced the risk of ESCC by $37 \%$ in the base model $(\mathrm{P}=0.01)$. Although no significant association was observe in the fully-adjusted model. In addition to that, the mean intake of $1.41 \mathrm{mg}$ vitamin $\mathrm{C}$ in comparison with the mean intake of $1.25 \mathrm{mg}$ reduced the risk of ESCC in both base and fully-adjusted models (base $\mathrm{P}=0.01$ and fully-adjusted $\mathrm{P}=0.01$ ). 
Hassani SS et al.

\begin{tabular}{|c|c|c|c|}
\hline Variable & Case $(n=47)^{a}$ & Control $(\mathbf{n}=96)^{\mathrm{a}}$ & P Value \\
\hline Sex & & & $0.89^{\mathrm{b}}$ \\
\hline Female & $29(62)$ & $58(60)$ & \\
\hline Male & $18(38)$ & $38(40)$ & \\
\hline Age, $y^{c}$ & $58 \pm 10.1$ & $58 \pm 10.4$ & $0.97^{\mathrm{d}}$ \\
\hline BMI, $\mathrm{kg} / \mathrm{m}^{2} \mathrm{C}$ & $20.5 \pm 3.2$ & $25.3 \pm 4.2$ & $0.00^{d}$ \\
\hline Physical activity ${ }^{\mathrm{C}}$ & $37.4 \pm 7.1$ & $35.2 \pm 7.8$ & $0.10^{d}$ \\
\hline Education & & & $0.34^{b}$ \\
\hline Illiterate & $42(89)$ & $80(83)$ & \\
\hline Literate & $5(11)$ & $16(17)$ & \\
\hline Job & & & $0.02^{b}$ \\
\hline Housewife & $19(41)$ & $5(52)$ & \\
\hline Unemployed & $1(2)$ & $12(13)$ & \\
\hline Employed & $27(57)$ & $34(35)$ & \\
\hline Reflux & & & $0.01^{b}$ \\
\hline Yes & $16(34)$ & $9(9)$ & \\
\hline No & $31(66)$ & $87(91)$ & \\
\hline Familiar cancer history & & & $0.01^{\mathrm{e}}$ \\
\hline Yes & $4(9)$ & $0(0)$ & \\
\hline No & $43(91)$ & $96(100)$ & \\
\hline Eating speed & & & $0.002^{b}$ \\
\hline Slow & $24(51)$ & $74(77)$ & \\
\hline Fast & $23(49)$ & $22(23)$ & \\
\hline $\begin{array}{l}\text { Food and beverage tempera- } \\
\text { ture }\end{array}$ & & & $0.01^{b}$ \\
\hline Hot & $32(68)$ & $15(16)$ & \\
\hline Cold & $15(32)$ & $81(84)$ & \\
\hline Cooking method & & & $0.01^{\mathrm{b}}$ \\
\hline Fried & $13(27)$ & $6(6)$ & \\
\hline Boiled & $18(39)$ & $70(73)$ & \\
\hline Both & $16(34)$ & $20(21)$ & \\
\hline Consumption of salty foods & & & $0.10^{\mathrm{e}}$ \\
\hline Salty and spicy & $3(6)$ & $1(1)$ & \\
\hline Non salty and spicy & $44(94)$ & $95(99)$ & \\
\hline Pepper consumption & & & $0.04^{b}$ \\
\hline Yes & $22(47)$ & $28(29)$ & \\
\hline No & $25(53)$ & $68(71)$ & \\
\hline Alcohol consumption & & & $1.00^{\mathrm{e}}$ \\
\hline Yes & $1(2)$ & $4(4)$ & \\
\hline No & $46(98)$ & $92(96)$ & \\
\hline Smoking & & & $0.26^{b}$ \\
\hline Never & $28(60)$ & $69(71)$ & \\
\hline Before & $11(23)$ & $13(14)$ & \\
\hline Current & $8(17)$ & $14(15)$ & \\
\hline Exposed to chemical gasses & & & $1.00^{\mathrm{e}}$ \\
\hline Yes & $3(6)$ & $7(7)$ & \\
\hline No & $44(94)$ & $89(93)$ & \\
\hline Body position during work & & & $0.41^{\mathrm{b}}$ \\
\hline Standing & $20(43)$ & $34(35)$ & \\
\hline Non standing & $27(57)$ & $62(65)$ & \\
\hline $\begin{array}{l}\text { a The values are presented as No. (\%) } \\
\mathrm{b} \chi^{2} \text { test was used. } \\
\mathrm{c} \text { The values are presented as mean }= \\
\text { d Independent t-test was used. } \\
\text { e Fisher test was used. }\end{array}$ & & & \\
\hline
\end{tabular}


Hassani SS et al.

\begin{tabular}{|c|c|c|c|}
\hline Micronutrients & Case $(n=47)$ & Control $(n=96)$ & P Value $^{\mathrm{b}}$ \\
\hline Vitamin A, $\mu$ gRE/day & $1124 \pm 598$ & $1339 \pm 741$ & 0.09 \\
\hline$\beta$-carotene, mg/day & $697 \pm 480$ & $836 \pm 562$ & 0.15 \\
\hline Vitamin E, mg/day & $6 \pm 6$ & $11 \pm 9$ & 0.00 \\
\hline$\alpha$-tocopherol, mg/day & $8 \pm 4$ & $8 \pm 4$ & 0.80 \\
\hline Vitamin C, mg/day & $109 \pm 63$ & $142 \pm 79$ & 0.01 \\
\hline
\end{tabular}

$\mathrm{a}$ The values are presented as mean \pm SD.

$\mathrm{b}$ Independent t-test was used.

Table 3. Relationship Between Antioxidant Vitamins Intake and Risk of Esophageal Squamous Cell Carcinoma in Case and Control Groups

\begin{tabular}{|c|c|c|c|c|}
\hline Variable & Number of Case Control & Mean \pm SD & Model 1 OR $(95 \% C I)^{a}$ & Model 2 OR $(95 \% \mathrm{CI})^{\mathrm{b}}$ \\
\hline \multicolumn{5}{|c|}{ Vitamin A, $\mu$ gRE/day } \\
\hline Tertile 1 & 23.25 & $576 \pm 1123$ & 1.00 & 1.00 \\
\hline Tertile 2 & 12.36 & $698 \pm 1327$ & $0.36(0.15-0.68)$ & $041(0.10-1.67)$ \\
\hline Tertile 3 & 12.35 & $809 \pm 1357$ & $0.37(0.16-0.89)$ & $0.65(0.14-2.97)$ \\
\hline P-trend & & & 0.02 & 0.47 \\
\hline \multicolumn{5}{|c|}{$\beta$-carotene, mg/day } \\
\hline Tertile 1 & 24.23 & $586 \pm 739$ & 1.00 & 1.00 \\
\hline Tertile 2 & 10.39 & $475 \pm 829$ & $0.25(0.01-0.60)$ & $0.38(0.09-1.58)$ \\
\hline Tertile 3 & 13.34 & $559 \pm 801$ & $0.37(0.16-0.86)$ & $0.69(0.16-3.08)$ \\
\hline P-trend & & & 0.01 & 0.52 \\
\hline \multicolumn{5}{|c|}{ Vitamin E, mg/day } \\
\hline Tertile 1 & 27.20 & $7 \pm 8$ & 1.00 & 1.00 \\
\hline Tertile 2 & 16.33 & $7 \pm 8$ & $0.36(0.16-0.83)$ & $0.25(0.06-1.04)$ \\
\hline Tertile 3 & 4.43 & $9 \pm 11$ & $0.07(0.02-0.22)$ & $0.11(0.02-0.59)$ \\
\hline P-trend & & & 0.01 & 0.00 \\
\hline \multicolumn{5}{|c|}{$\alpha$-tocopherol, mg/day } \\
\hline Tertile 1 & 14.33 & $4 \pm 8$ & 1.00 & 1.00 \\
\hline Tertile 2 & 15.34 & $4 \pm 9$ & $1.04(0.44-2.49)$ & $0.42(0.09-1.89)$ \\
\hline Tertile 3 & 18.29 & $3 \pm 8$ & $1.46(0.62-3.45)$ & $0.85(0.20-3.65)$ \\
\hline P-trend & & & 0.38 & 0.80 \\
\hline \multicolumn{5}{|c|}{ Vitamin C, mg/day } \\
\hline Tertile 1 & 29.18 & $80 \pm 125$ & 1.00 & 1.00 \\
\hline Tertile 2 & 11.38 & $69 \pm 128$ & $0.18(0.07-0.44)$ & $0.02(0.002-0.17)$ \\
\hline Tertile 3 & 7.40 & $77 \pm 141$ & $0.11(0.04-0.29)$ & $0.02(0.002-0.30)$ \\
\hline P-trend & & & 0.01 & 0.00 \\
\hline
\end{tabular}

a Base model, adjusted for age (years) and sex (male/female).

b Fully-adjusted model, adjusted for cooking method, reflux signs, eating speed, food preference, job, and BMI. 


\section{Discussion}

The results of this study showed reduced risk of ESCC according to high intake of antioxidant vitamins. Since these nutrients reflect the general dietary pattern and can be linked together and depend largely, so judgment in protective effects of a special food or a combination of them is a little difficult

By using multifactorial analysis, we could determine that vitamin $\mathrm{E}$ and $\mathrm{C}$ have a strong relation with the risk of ESCC, while no relation was founded between vitamin A, $\beta$-carotene, $\alpha$-tocopherol and the risk of ESCC.

It is known that diets rich in vegetables, fruits, vitamins and antioxidants are generally protective against development of digestive tract cancers [10]. These food groups supply micro nutrients such as vitamin A, C, E carotenoids, antioxidants and fiber which prevent cancer [11]. A recent research in Sudan evaluated the relationship of antioxidants (vitamin C, vitamin E and $\beta$-carotene) intake and esophageal cancer, which reported these nutriments have an inverse relation to the risk of both types of ESCC and EAC (esophageal adenocarcinoma) [10]. Franceschi et al. [12] examined the effect of vitamins and minerals on risk of ESCC and found an inverse relation between $\beta$-carotene, vitamin C, E and the risk of this cancer. Other observational studies also report that these antioxidant nutrients are inversely associated with the risk of esophageal cancer [13]. The results of a prospective study suggest that vitamin E may have different effects on different subtypes of esophageal cancer. Dietary $\alpha$-tocopherol had a significant inverse association with ESCC and GCA (Gastric cardia adenocarcinoma) risk in age and sex adjusted model but this was substantially attenuated in fully adjusted model [13]. Also, the results of our study showed no relation between dietary $\alpha$-tocopherol and the risk of ESCC. Results of case-control and prospective studies confirmed the different effect of $\alpha$-tocopherol against esophageal cancer [14]. It seems that the major function of vitamin $\mathrm{E}$ is prevention of lipid peroxidation in cell membrane, lipoproteins and fat stores [15]. In Wolfgarten et al. [16] research, vitamin E significantly reduced the risk of esophageal cancer. In our study higher intake of vitamin $\mathrm{E}$ was associated with reduction in risk of ESCC.

A case-control study showed that receiving more than $13 \mathrm{mg} /$ day vitamin $\mathrm{E}$ and more than $100 \mathrm{mg} /$ day vitamin $\mathrm{C}$ reduce the risk of ESCC [17]. The German Nutritional Society's recommended daily allowance of vitamin E is $12 \mathrm{mg}$ and higher doses are recommended to avoid peroxide formation [15].

In our study, the daily intake was less than recommended values in both groups and this deficiency was higher in the case group. Other studies in very high incidence areas of EC (Esophageal cancer), such as north of Iran, Linxian, China, north and east of Siberria and Hungary showed that dietary intake of vitamin $C$ through fruits and vegetables inversely associated with EC [18]. A significant risk reduction was reported between monthly consumption of vitamin C and esophageal cancer among white men in NewYork [19].
Five times reduction in risk has been shown in the highest tertile intake of fruits and vegetables too [20].

In our study, vitamin $\mathrm{C}$ was inversely associated with risk of ESCC. Most researchers believe that vitamin $C$ has a preventive role in cancer cells development. The opinion that there are mechanisms by which the vitamin C may act by protecting against carcinogenesis is controversial, and several hypotheses are raised. The main mechanism and action of vitamin $C$ in the prevention of cancerous cells formation can be due to the capacity of this nutrient in decreasing nitrous acid and preventing the formation of nitrosamines in stomach [21]. Based on measures of the ascorbic acid in the gastric juice and gastric $\mathrm{pH}$, Schorah et al. [22], observed that the nitrosation depends on the gastric acid secretion, of the $\mathrm{pH}$ and the bacterial synthesis at high $\mathrm{pH}$. They demonstrated that the $300 \mathrm{~mol} / \mathrm{L}$ is the ideal concentration of ascorbic acid to inhibit nitrosation, which occurs in humans with a daily oral ingestion of $200 \mathrm{mg}$ of vitamin C. The Committee on Diet, Nutrition, and Cancer of the National Academy of Sciences showed in 1982, that the vitamin C inhibits the formation of some carcinogens and also the consumption of foods rich in vitamin C would be associated with low risk of esophageal carcinoma [15]. There are many soundings about recommended allowable values of vitamin C. Authors, such as Levine et al. [23] suggest a daily ingestion of $100-120 \mathrm{mg} /$ day, through the daily consumption 5 portions of fruits and vegetables, and a maximum of $1 \mathrm{~g} /$ day, as a safe measure to avoid adverse effects of excessive Ingestion [24]. In our study, the mean intake of vitamin C was $109 \mathrm{mg} /$ day for the cases and $142 \mathrm{mg} /$ day for the controls which is more than RDA (Recommended Dietary Allowances). Free radicals can react in carcinogenesis, causing DNA oxidative lesions or cell wall damage, facilitating the entrance and action of carcinogens, such as the nitrosamines, which are very important in the formation of tumors and considering that vitamin $\mathrm{C}$ is an antioxidant, it would act by supplying electrons for neutralization of the free radicals [25, 26]. A large intervention trial in China, however, has failed thus far to see a reduction in the incidence of esophageal or gastric cancer in persons given supplemental vitamin C (120 mg/day) along with molybdenum (30 mg/day) for 5.25 years, which suggests that the protective effect of vitamin C, if real, occurs early in the carcinogenic process [27].

In comparison with vitamin $C$, a weaker inverse but clear relationship was observed with the intake of vitamin $\mathrm{A}$ [20]. Most of researches showed a protective effect of vitamin A [28-31]. Subsequently, a lot of studies showed an obvious relation between $\beta$-carotene intake and risk of ESCC $[28,30,31]$. However, a number of studies did not report any relation between $\beta$-carotene intake and risk reduction [3234]. In our study, $\beta$-carotene reduced the risk of ESCC to $37 \%$, only in base model. Even though, no information is available as the daily requirements of $\beta$-carotene in Germany, 2 - $4 \mathrm{mg}$ of $\beta$-carotene are recommended as the daily dose for 
adults. The German Nutritional Society recommends $1 \mu \mathrm{gE}$ daily intake of vitamin A for adults [15]. Which in our study the daily intake in both case and control groups was more than this value. Although, we could control the effect of many disturbing variables relating to the life style in this study, but we cannot ignore the possible effect of the rest disturbing factors (residual confounding), also there is the probability of recall bias due to the type of study too. So it is better to perform studies with more samples to increase the power of the study. Also the nutrients association with esophageal cancer should consider in prospective studies to evaluate and prove a powerful causal relation. Generally, the results of this study suggest that antioxidant vitamins can possibly play a protective role in preventing risk of squamous cell carcinoma.

\section{Acknowledgements}

This article is part of the thesis "Risk of Squamous Cell Carcinoma of Esophagus and Dietary Nutrients in Kurdistan province" with registration number 117, which is performed by the author's own funds.

\section{Funding/Support}

Shahid Beheshti University of Medical Sciences, Tehran

\section{References}

1. Mehrabi Y, Yavari P, Abadi A. A study of cancer patterns among inpatients of public hospitals in Iran. Asian Pac J Cancer Prev. 2004;5(4):387-92.

2. World Health Organization. All cancers (excluding non-melanoma skin cancer) estimated incidence, mortality, and prevalence worldwide in 2012. WHO; 2012. Available from: http://globocan.iarc.fr/ Pages/fact_sheets_cancer.aspx.

3. Ghavamzadeh A, Moussavi A, Jahani M, Rastegarpanah M, Iravani M. Esophageal cancer in Iran. Semin Oncol. 2001;28(2):153-7.

4. Siassi F, Pouransari Z, Ghadirian P. Nutrient intake and esophageal cancer in the Caspian littoral of Iran: a case-control study. Cancer Detect Prev. 2000;24(3):295-303.

5. Hormozdiari H, Day NE, Aramesh B, Mahboubi E. Dietary factors and esophageal cancer in the Caspian Littoral of Iran. Cancer Res. 1975;35(11 Pt. 2):3493-8.

6. Siassi F, Ghadirian P. Riboflavin deficiency and esophageal cancer: a case control-household study in the Caspian Littoral of Iran. Cancer Detect Prev. 2005;29(5):464-9.

7. Lopez-Garcia E, Schulze MB, Fung TT, Meigs JB, Rifai N, Manson JE, et al. Major dietary patterns are related to plasma concentrations of markers of inflammation and endothelial dysfunction. Am J Clin Nutr. 2004;80(4):1029-35.

8. Mirmiran P, Esfahani FH, Mehrabi Y, Hedayati M, Azizi F. Reliability and relative validity of an FFQ for nutrients in the Tehran lipid and glucose study. Public Health Nutr. 2010;13(5):654-62.

9. Esfahani FH, Asghari G, Mirmiran P, Azizi F. Reproducibility and relative validity of food group intake in a food frequency questionnaire developed for the Tehran Lipid and Glucose Study. $J$ Epidemiol.2010;20(2):150-8.

10. Taylor PR, Li B, Dawsey SM, Li JY, Yang CS, Guo W, et al. Prevention of esophageal cancer: the nutrition intervention trials in Linxian, China. Linxian Nutrition Intervention Trials Study Group. Cancer Res. 1994;54(7 Suppl):2029s-31s.

11. Rashidkhani B, Hajizadeh-Armaki B, Houshiar-Rad A, Moasheri M. Dietary patterns and risk of squamous-cell carcinoma of esophagus in Kurdistan province, Iran [in Persian] . Iran J Nutr Sci Food Technol. 2008;3(3):11-21.

12. Franceschi S, Bidoli E, Negri E, Zambon P, Talamini R, Ruol A, et al. Role of macronutrients, vitamins and minerals in the aetiology of squamous-cell carcinoma of the oesophagus. Int J Cancer 2000;86(5):626-31.

13. Carman S, Kamangar F, Freedman ND, Wright ME, Dawsey SM Dixon LB, et al. Vitamin E intake and risk of esophageal and gastric cancers in the NIH-AARP Diet and Health Study. Int J Cancer. 2009;125(1):165-70.

14. Abnet CC, Chen W, Dawsey SM, Wei WQ, Roth MJ, Liu B, et al. Serum 25(OH)-vitamin D concentration and risk of esophageal squamous dysplasia. Cancer Epidemiol Biomarkers Prev. 2007;16(9):1889-93.

15. Bollschweiler E, Wolfgarten E, Nowroth T, Rosendahl U, Monig SP Holscher AH. Vitamin intake and risk of subtypes of esophagea cancer in Germany. J Cancer Res Clin Oncol. 2002;128(10):575-80.

16. Wolfgarten E, Rosendahl U, Nowroth T, Leers J, Metzger R, Holscher AH, et al. Coincidence of nutritional habits and esophageal cancer in Germany. Onkologie. 2001;24(6):546-51.

17. Chen X, Mikhail SS, Ding YW, Yang G, Bondoc F, Yang CS. Effects of vitamin $\mathrm{E}$ and selenium supplementation on esophageal adenocarcinogenesis in a surgical model with rats. Carcinogenesis 2000;21(8):1531-6.

18. Rodler I, Zajkas G. Hungarian cancer mortality and food avail ability data in the last four decades of the 20th century. Ann Nutr Metab. 2002;46(2):49-56.

19. Mettlin C, Graham S, Priore R, Marshall J, Swanson M. Diet and cancer of the esophagus. Nutr Cancer. 1981;2(3):143-7.

20. Fontham ET, Su LJ. Prevention of cancers of the esophagus and stomach. In: Bendich A, Eckelbaum RJ, editors. Preventive nutrition. 3rd ed. New Jersey: Humana Press; 2005.

21. Hoefert S, Bloch T, Wierich W, Eufinger H. [Rare entity of a macroscopically visible tumor cone of squamous cell carcinoma in the greater veins of the head and neck]. Mund Kiefer Gesichtschir 2006;10(1):46-9.

22. Schorah CJ, Sobala GM, Sanderson M, Collis N, Primrose JN. Gastric juice ascorbic acid: effects of disease and implications for gastric carcinogenesis. Am J Clin Nutr. 1991;53(1 Suppl):287S-93S.

23. Levine M, Rumsey SC, Daruwala R, Park JB, Wang Y. Criteria and recommendations for vitamin C intake. JAMA. 1999;281(15):1415-23.

24. Ramos AC, Araujo MR, Lopes LR, Andreollo NA. Role of the vitamin $C$ in diethylnitrosamine-induced esophageal cancer in Wistar rats. Acta Cir Bras. 2009;24(3):183-8.

25. Grdisa M, Kralj M, Eckert-Maksic M, Maksic ZB, Pavelic K. 6-Amino6-deoxyascorbic acid induces apoptosis in human tumor cells. Cancer Res Clin Oncol. 1995;121(2):98-102.

26. Fraga CG, Motchnik PA, Shigenaga MK, Helbock HJ, Jacob RA, Ames BN. Ascorbic acid protects against endogenous oxidative DNA damage in human sperm. Proc Natl Acad Sci U S A.1991;88(24):11003-6.

27. Wang GQ, Dawsey SM, Li JY, Taylor PR, Li B, Blot WJ, et al. Effects of vitamin/mineral supplementation on the prevalence of histological dysplasia and early cancer of the esophagus and stomach: results from the General Population Trial in Linxian, China. Cancer Epidemiol Biomarkers Prev.1994;3(2):161-6.

28. Gao YT, McLaughlin JK, Gridley G, Blot WJ, Ji BT, Dai Q, et al. Risk factors for esophageal cancer in Shanghai, China. II. Role of diet and nutrients. Int J Cancer.1994;58(2):197-202.

29. Tzonou A, Lipworth L, Garidou A, Signorello LB, Lagiou P, Hsieh $\mathrm{C}$, et al. Diet and risk of esophageal cancer by histologic type in a low-risk population. Int J Cancer. 1996;68(3):300-4.

30. Mayne ST, Risch HA, Dubrow R, Chow WH, Gammon MD, Vaughan $\mathrm{TL}$, et al. Nutrient intake and risk of subtypes of esophageal and gastric cancer. Cancer Epidemiol Biomarkers Prev. 2001;10(10):1055-62.

31. Ziegler RG, Morris LE, Blot WJ, Pottern LM, Hoover R, Fraumeni JJ Esophageal cancer among black men in Washington, D.C. II. Role of nutrition. J Natl Cancer Inst. 1981;67(6):1199-206.

32. Launoy G, Faivre J, Pienkowski P, Milan C, Gignoux M, Pottier D. Changing pattern of oesophageal cancer incidence in France. Int JEpidemiol.1994;23(2):246-51.

33. Tavani A, Negri E, Franceschi S, La Vecchia C. Risk factors for esophageal cancer in lifelong nonsmokers. Cancer Epidemiol Biomarkers Prev. 1994;3(5):387-92.

34. Hu J, Nyren O, Wolk A, Bergstrom R, Yuen J, Adami HO, et al. Risk factors for oesophageal cancer in northeast China. Int J Cancer 1994;57(1):38-46 